yellow in ultraviolet light. Marker spots of $\mathrm{B}_{2}$ and HEF were applied at the origin alongside the test spots. $R_{f}$ values of $\mathrm{B}_{2}, \mathrm{HEF}$ and FMF in this system are 0.40 , 0.53 and 0.63 respectively but there were no yellow spots at or near 0.53 or 0.63 though the $\mathrm{B}_{2}$ was prominent at 0.40 . Yellow-fluorescent spots of $R_{f}<0.40$ were from the medium itself. All the bacteria except Streptococcus bovis showed a yellowfluorescent spot at 0.87. The species tested were Butyrivibrio sp, Lactobacillus bifidus, Escherichia coli, Veillonella gazogenes, Peptostreptococcus sp, Lact, fermenti, Strep. bovis and Selenomonas ruminantium. However later isolations of rumen bacteria from $\mathrm{B}_{2}$-enriched media have confirmed that some unidentified rumen bacteria can produce HEF or FMF or other metabolites of $B_{2}$. Isolated pure cultures of these are being studied for classification.

\title{
REFERENCES
}

Owen, E. C. (1962). Proc. int. Congr. Fd Sci. Technol. I. London. Vol. 3, p. 669. Owen, E. C. \& West, D. W. (r968). F. chem. Soc. (C) p. 34.

\section{A hypothetical mechanism for the regulation of food intake in relation to energy balance. By G. R. HERveY, Department of Physiology, School of Medicine, University of Leeds}

Animals take in and expend amounts of energy which over long periods are found to be equal within the limits of practical measurement. Since any difference between energy gain and loss necessarily alters the store of energy in the body, and this is in chemical form, the maintenance of a near-constant adult body-weight depends upon maintaining energy balance. If the difference between energy intake and output is calculated from the changes which typically do occur in body-weight over significant parts of the life-span, the error of balancing, as a fraction of the total turnover, is seen to be extremely small. Near-equality of energy intake and output could be achieved by physiological regulation of either or both. Adjustment of food intake in relation to energy balance can be readily demonstrated, for example by changing the calorie concentration of the diet; adjustment of energy expenditure occurs if intake is restricted, but is otherwise controversial.

Whatever the effector, the information used in energy balancing is a problem. Since there is no correlation between energy intake and output over short periods such as a day, and the accuracy of adjustment is higher the longer the period considered, one possibility is that the level of energy stores in the body is monitored. It is the purpose of this communication to suggest how this could be done. The proposal stems from two lines of experiment: (r) experiments with parabiotic rats suggesting a blood-borne signal to the hypothalamus; (2) the apparently centrally integrated effects of hormonal and synthetic steroids on body-weight, fat content, food intake and activity.

The suggestion is that a humoral agent could measure the amount of fat in the body by the dilution principle. If (like some steroids) it had a high fat: water partition 
coefficient, and if there were a constant amount of it in the body, then the concentration in the aqueous phase would be higher the less fat was present, and vice versa. If the hypothalamus responded to the substance (as it appears to do to some steroids) by calling for increased food intake and possibly decreased energy expenditure, a feedback system would exist which would tend to stabilize body fat content; and in so doing to equalize energy intake and output. There is at present little evidence to show whether this is the mechanism used by the body; it is, however, suggested that some hitherto unconsidered mechanism must exist to account for the observed properties of energy balancing.

Protein content of the diet and food intake in steers. By M. KAY, N. A. MACLEOD and A. MACDEARMID, Rowett Research Institute, Bucksburn, Aberdeen $A B 2$ 9SB

In trials in which concentrate diets were given to appetite we found that diets containing $14 \%$ crude protein in the dry matter promoted greater food intakes and faster growth rates than those containing i $\%$. The two experiments described below were made to determine whether the difference in growth was entirely a consequence of that in food intake.

In the first, seven pairs of Friesian steers were used in a double reversal trial to compare the effects on growth rate of diets containing either I $\%$ or $14 \%$ crude protein in dry matter but rationed so that equal amounts of calculated metabolizable energy (ME) were consumed daily. In the second, six trios of steers were used in a reversal trial to compare the effects on growth rate of a basal diet of barley containing $9.5 \%$ crude protein in the dry matter with or without the addition of urea or soyabean meal added to give $13 \%$ crude protein in the dry matter. Steers given the supplemented diets were rationed so that calculated $\mathrm{ME}$ intakes were equal. In addition, four steers with rumen fistulas were fed to appetite on the same basal diet but were given soya-bean meal or urea by mouth or fistula in order to study the separate effects of palatability and rate of digestion.

In the first trial, the daily live-weight gain was $0.90 \mathrm{~kg}$ daily and $1.07 \mathrm{~kg}$ daily ( $\mathrm{sE} \pm 50 \mathrm{~g}$ ) when the steers were given the low-protein diet and the high-protein diet respectively. In the second trial, steers given the basal diet grew at $0.92 \mathrm{~kg}$ daily whereas those given either urea or soya-bean meal grew at $1 \cdot 14 \mathrm{~kg}$ daily (SE \pm $140 \mathrm{~g}$ ). The differences in gain in the second trial were not statistically significant. In the fistulated steers, the intake of the basal diet was increased by both of the nitrogen supplements; the effects of the two routes of administration will be discussed.

It thus appears that the faster growth rate promoted in steers by diets higher in protein is not simply a reflection of greater food intake.

The influence of protein concentration in concentrate feeds on the apparent disappearance of dry matter, protein, starch, ether extract and ash in various segments of the digestive tract in sheep. By E. R. ØRSKov and C. Fraser, Rowett Research Institute, Bucksburn, Aberdeen AB2 $9 S B$ 